Portland State University

PDXScholar

\title{
Serpent, Shadow, \& Cyborg: Active Interpretation in a Sea of Information
}

\section{Sara Karl}

Portland State University

Follow this and additional works at: https://pdxscholar.library.pdx.edu/honorstheses

\section{Let us know how access to this document benefits you.}

\section{Recommended Citation}

Karl, Sara, "Serpent, Shadow, \& Cyborg: Active Interpretation in a Sea of Information" (2018). University Honors Theses. Paper 523.

https://doi.org/10.15760/honors.528

This Thesis is brought to you for free and open access. It has been accepted for inclusion in University Honors Theses by an authorized administrator of PDXScholar. Please contact us if we can make this document more accessible: pdxscholar@pdx.edu. 
Serpent, Shadow, \& Cyborg: Active Interpretation in a Sea of Information

by

\section{Sara Karl}

An undergraduate honors thesis submitted in partial fulfillment of the requirements for the degree of

Bachelor of Arts

in

University Honors

and

Art Practice

Thesis Adviser

Sabina Haque

Portland State University 


\section{Background:}

Understanding how we interpret the information that saturates the world around us gives us vital information about the self, the experience of perception, through which we can better understand the information interpreted. Information is scattered all around us in daily life but it's also presented in the form of stories, patterns that seem to inform us about life through example in the form of play, fiction, and dreams. The short animated film, Serpent, Shadow, \& Cyborg, is a retelling of Genesis, the Christian creation myth, that explores the way in which stories and storytelling can inform us about how we experience information and how that impacts the way we project in society.

The creation process of my thesis project mirrors the idea of the process of interpretation that I am exploring within the film. At first I was initially drawn to explore how altering the role of Eve could change western perceptions of gender roles. When I started actually making the film and developing imagery, I realized that I was less interested in literally interpreting what was happening but more interested in how I was interpreting the story. The various feminist critiques of Genesis that I read made arguments that I found to be true because they were relatable, but ultimately they were all doing the same thing which, was interpretation. I found that the process of making the film informed me about it's content better than the end product itself because my own psychological processes were mirrored back to me in the process of creation just as they are during the process of interpretation.

Through the process of studying dreams and developing analysis methods Carl Jung (Swiss psychologist, psychiatrist, and founder of analytic psychology) was led to theorize about what he called the archetypes. An archetype, according to Jung, "does not proceed from physical facts, but describes how the psyche experiences the physical fact". It is a "psychic organ present in all of us," that is to say a mental process with which humans are equipped. The archetypes can be sensed but they remain so obscure that the only way to talk about them is through symbols.

\footnotetext{
${ }^{1}$ Jung, C., The Archetypes and the Collective Unconscious, (Princeton, NJ: Princeton University Press. 1990), 154.
} 
Jung and Sigmund Freud were exploring the nature of interpreting dreams around the same time in the early 20th century. However, Jung disagreed with Freud's method of dream interpretation. Contrary to Freud's theories, Jung believed that whatever symbol was present in the individual's dream will have a meaning that is specific only to the dreamer saying that, "No dream symbol can be separated from the individual who dreams it". ${ }^{2}$ He observed the way that archetypes appeared in the dreams of his patients and how that could inform them of their current psychological state. It isn't simply enough to point out that a dream contains the symbol of an apple, for example, but it's important to also think about why the unconscious mind chose the apple to be in the dream when it could have been any other object. This is why Jung stressed the fact that a symbol, and the archetypes, can only be experienced on an individual level because one can only experience their physical reality through their own perception. No matter how similar they may seem, the sensorial relationship with a symbol is unique, no person can have the same exact relationship with it.

The body senses the world physically through touch, taste, sound, smell, and sight and is in turn processed by the mind. In this way, thought acts as a sixth sense, because it is a part of our perception of the world. The mind is responsible for sorting and filing the information received from the other five senses. A sensory experience, i.e. multiple perceptions by all senses simultaneously, can never be exactly the same for any one individual because of the nature of time. The symbol can never be separated from the individual dreamer/perceiver because the understanding of that symbol is a unique relationship of meaning conceived by the mind of the individual for the well being of the archetype that the symbol indicates. If we understand that archetypes behave in a manner similar to our organs or cells neglecting or abusing them will negatively affect our well being:

A bad explanation means a correspondingly bad attitude to this organ, which may thus be injured. But the ultimate sufferer is the bad interpreter himself. Hence the 'explanation' should always be

\footnotetext{
${ }^{2}$ Jung, C. G., Von Franz, M. L., Henderson, J. L., Jacobi, J., \& Jaffe, A., Man and his Symbols, (New York, NY: Ferguson Publishing 1964), 53
} 
such that the functional significance of the archetype remains unimpaired, so that an adequate and meaningful connection between the conscious mind and the archetypes is assured. For the archetype is an element of our psychic structure and thus a vital and necessary component in our psychic economy. $^{3}$

The bad interpreter is the one punished for the bad explanation of the archetype because they have abused their relationship with that aspect of their psyche. Those who are influenced by or choose to believe the bad interpretation are harmed as well. Archetypal wellbeing is compromised if the meaning of a symbol were to stagnate. If the symbol were to have a fixed meaning it would no longer be a symbol but a sign, "The sign is always less than the concept it represents, while a symbol always stands for something more than its obvious and immediate meaning". ${ }^{4}$ An explanation of the symbol should necessarily be in flux and change with the person or social group that is also in a constant physical state of change. The function of a symbol is to represent something that we experience but can never fully understand with our senses. The sign stands only for its immediate meaning and does not address that which is unknown to us so it remains fixed. The symbol always contains the unknown which is why it can never have a fixed meaning like a sign.

The way to ensure a "meaningful connection between the conscious mind and the archetypes" is through the understanding of interpreting symbols. For Jung, that was specifically the interpretation of symbols in dreams but as Joseph Campbell puts it, "The myth is the public dream and the dream is the private myth" so the same theories can be applied. ${ }^{5}$

\footnotetext{
${ }^{3}$ Jung, The Archetypes, 160

${ }^{4}$ Jung, Man and his Symbols, 55

${ }^{5}$ Campbell, J., Moyers, B., The Power of Myth, (New York, NY: Doubleday 1988), 48
} 


\section{Form:}

The form is integral to the story because it deals with the concept of perception. Animation was the appropriate medium for this project because just as we animate images to look as if there is motion, we give animate qualities to symbols so they seem to have a meaning beyond what they really are. Animated pictures are not what they represent, it's change over time that makes us perceive the pictures to be something other than what they are, i.e. in motion. Similarly, symbols are not what they represent, it is the psychic process of interpretation that allows the symbol to be perceived with a particular meaning or multiple meanings.

The animation transitions from computer generated images to stop motion made with paper cutouts and painted backgrounds. It transitions again from stop motion to digitally animated photo collage and computer generated imagery. The stop motion animation is the most abstract form of representation in the film. The characters are flat, have limited movement, and there is a limited sense of depth. This section of the film is really where the viewer is asked to use their imagination to fill in the gap between abstract representation and the way in which they perceive the world around them. The more abstract a symbol is the more the mind searches for possible meanings in order to interpret the symbol.

The photo collage and computer generated imagery are more recognizable but they still remain abstract because they are only representations of reality, they will always be symbols as long as there is interpretation of the story. The photo collage is the most "realistic" form of representation in the film but pulling the photos from their original context and using them to create new images reveals their symbolic properties. The photos no longer have the same meaning but they still have meaning. The computer generated imagery represents how technology is an extension of the senses and therefore expands the range of information that is in the conscious mind. The simulated stars, sun, and cells are more realistic but they also reveal that any depiction of their form will contain symbolic meaning because the representation will never be object. 


\section{Symbols and Themes:}

The main symbols in this film are the circle and serpent, shadow, and the cyborg. Each symbol offers ideas about perception and perspective that inform the meaning of the story as well as ideas to inform the viewer to their active interpretation.

The circle is repeated in many different forms representing biological forms as well as philosophical ideas. The sun and cells in the beginning of the film represent the macro and micro scale of life, or rather the repeated patterns that work together to make our lives possible. The circle is an important symbol for us not only because of how we relate to it physically but also how we mentally relate to it. Joseph Campbell notes that the circle has both a spatial aspect, that contains or "encircles" whatever is within, and a temporal aspect, leaving, going somewhere and coming back to the place where one left in the first place. ${ }^{6}$ The temporal aspect of the circle mimics our own biological cycle of life and death and the seasons. It is also a symbol representing the concept of infinity.

The circle and the serpent intertwine as symbols of the cycle of life and time. Because the snake sheds its skin, it has become a symbol of life, regeneration, immortality, and wisdom among other things in various cultures. ${ }^{7}$ According to Campbell, "The serpent represents immortal energy and consciousness engaged in the field of time, constantly throwing off death and being born again [...] (it) is the lord of the central tree, where time and eternity come together. He (the serpent) is the primary god, actually, in the Garden of Eden". ${ }^{8}$ Walker-Jones suggests that a reading of genesis that focuses on the serpent could, "decenter the heterosexual couple and deconstruct the dualism of male and female". ${ }^{9}$ Both Campbell and Walker-Jones put forth an interesting idea of focusing on the role of the snake which, becomes more complex when it's understood to represent concepts of time. When time is thought of as a circle rather

\footnotetext{
${ }^{6}$ Ibid, 269

${ }^{7}$ Walker-Jones, A., “Eden for Cyborgs: Ecocriticism and Genesis 2-3.” Biblical Interpretation, (2008), 280.

${ }^{8}$ Campbell, The Power of Myth, 53-54.

${ }^{9}$ Walker-Jones, "Eden for Cyborgs", 286.
} 
than a line it represents a cyclical but infinite pattern. So at any point on the circle total perception is possible. These ideas influenced my decision about how the roles of "God" in the traditional telling would be retold through other characters.

When the circle and the snake come together in one symbol it creates the ouroboros, or the snake that eats its own tail. The snake eating its own tail is symbolic of the cycle of consumption and regeneration coupled with the shape of a circle representing the temporally cyclical aspect of life and death. The ouroboros first appears in the film during the transition from computer generated animation and stop motion animation. While the sun, stars and cells are symbols in their own right, the ouroboros is the first constructed (i.e. human-made) symbol to appear, signifying the "beginning" of the myth in the film and the point on the homo sapien timeline in which creating and using symbols became a part of our lives.

The symbol of the shadow appears when Adam is confronted with "knowledge" by eating fruit from the tree of knowledge. In knowing, there will always be that which is known and unknown, the conscious and unconscious. One always knows that they're perception will always contain a limitation. From this realization, Adam's shadow appears. The shadow is in reference to what Jung called the "shadow" archetype:

The individuation process is invariably started off by the patient's becoming conscious of the shadow, a personality component usually with a negative sign. This "inferior" personality is made up of everything that will not fit in with, and adapt to, the laws and regulations of conscious life. It is compounded of "disobedience" and is therefore rejected not on moral grounds only, but also for reasons of expediency. ${ }^{10}$

\footnotetext{
${ }^{10}$ Jung, C. G., and Robert Alan. Segal. On Mythology, (London: Routledge, 1998), 87.
} 
The part of the personality that is rejected by the individual becomes repressed; it is an integral part of the archetype and cannot be removed. Jung suggests that, "In reality we can never legitimately cut loose from our archetypal foundations unless we are prepared to pay the price of a neurosis, any more than we can rid ourselves of our body and its organs without committing suicide". ${ }^{11}$ The attempt to cut loose from any archetype results in a complex, i.e. "repressed emotional themes that can cause constant psychological disturbances". ${ }^{12}$ After confronting Adam's shadow Eve's shadow takes form and morphs with Adam's suggesting that the shadow is not only the result of a personal complex but can also be a social complex:

Just as personal complexes have their individual history, so do social complexes of an archetypal character. But while personal complexes never produce more than a personal bias, archetypes create myths, religions, and philosophies that influence and characterize whole nations and epochs of history. ${ }^{13}$

When an archetype is only interpreted as its shadow characteristics the interpreter forms a negative relationship with that aspect of the psyche. The danger lies in the potential of a whole society that has a negative relationship with that aspect of the psyche, thus creating a cultural or social shadow. The physical appearance of the shadow is almost comical, it remains 2D and black and white monochrome throughout the film. There are no other dimensional qualities about the shadow because it stands for only one part of the psyche that remains unintegrated, that is, until the appearance of the cyborg.

In the latter half of the film, the skull split in two represents the way in which we perceive the phenomena that we call duality. The background behind the skull shifts from night to day and rural to urban and then the onset of a storm. Time has passed and the dual split remains but it is washed away and a new character appears. The character that emerges from the shadow after the storm is a cyborg,

\footnotetext{
${ }^{11}$ Jung, The Archetypes, 157

${ }^{12}$ Jung, Man and his Symbols, 27

${ }^{13}$ Ibid. 79
} 
referencing the concept developed by Donna Haraway. She explains that the cyborg myth, "is about transgressed boundaries, potent fusions and dangerous possibilities which progressive people might explore as one part of needed political work". ${ }^{14}$ The cyborg is an idea of perception, the idea that there is a multiplicity of experience that is not limited to the experience of the ego. Dualistic perception is an elementary understanding brought about by the process of individuation but is problematic in that it no longer serves to interpret the archetype in functional way. The multiplicity of experience refers to combination of sensorial experience that is not from one source alone. Campbell states that we perceive the world in opposites because, "we can't think otherwise". ${ }^{15}$ Rather, we don't think otherwise because we are contained in a language that is based on dualistic perception.

If it is true that our "physical" senses limit how we perceive the world then surely thought is also contained within a range that can be understood by the human mind but that is not to say it is the limit of thought. For example, we can only perceive certain electromagnetic waves with our eyes but that's not to say that there isn't any other form of wave happening around us just because we can't see it. Similarly, the individual person can only perceive what they are thinking but that's not to say that there isn't more than just their own thinking that is happening. The cyborg helps in the understanding that technological developments are merely extensions of our senses. Haraway asks:

Why should our bodies end at the skin, or include at best other beings encapsulated by skin?

From the seventeenth century till now, machines could be animated - given ghostly souls to make them speak or move or to account for their orderly development and mental capacities. Or organisms could be mechanized - reduced to body understood as resource of mind. ${ }^{16}$

\footnotetext{
${ }^{14}$ Haraway, D., “A Cyborg Manifesto” (D. Bell \& B. M. Kennedy, Eds.) The Cybercultures Reader. 2000, 295.

${ }^{15}$ Campbell, The Power of Myth, 57

${ }^{16}$ Haraway, "A Cyborg Manifesto", 313.
} 
Viewing the human body as a series of mechanized processes carried out by cells is a way to subvert the dualistic perception of human and machine as oppositional. Machines are not opposed to us in the understanding that they are extensions of processes that our bodies are capable of. They extend our perception of reality and necessarily cannot be removed from the experience of the perception. The cyborg suggests that the more our technology expands the more our consciousness, that which we know, expands. For this reason, Haraway stresses the fact that it's important to know who is controlling that technology, that extension of sensory perception, and therefore our consciousness. In juxtaposing the theories of Haraway and Jung, the cyborg can be seen as the conscious integration of the archetype. The cyborg is one who is aware of all aspects of their psyche through the way that it processes information. Therefore in the film, the cyborg is the one capable of illuminating and integrating with the shadow creating a multiplicity of experience rather than a dualistic experience.

\section{Conclusion}

The amount of information that surrounds us daily feels overwhelming and frightening but the cyborg tells us that, "A slightly perverse shift of perspective might better enable us to contest for meanings, as well as for other forms of power and pleasure in technologically mediated societies". ${ }^{17} \mathrm{~A}$ shift in perspective means being aware of perspective in the first place. The perverse shift that Haraway suggests not only requires that the individual take control of their perspective but to also change the symbols and language that no longer serve to describe reality as it is experienced. When our mind can play with ideas and concepts in simplified ways we can better navigate similar patterns in our daily life and adapt our thinking accordingly. This is why storytelling is still such a vital part of our life especially with the rate at which our technology changes. Stories provide patterns for navigating through the chaos

\footnotetext{
${ }^{17}$ Ibid. 295
} 
that is the universe, and just like with any kind of technology the qualities they possess are the ones we project. 
Bibliography

Campbell, J., Moyers, B. The Power of Myth. New York, NY: Doubleday, 1988.

Haraway, D. “A Cyborg Manifesto” (D. Bell \& B. M. Kennedy, Eds.). The Cybercultures Reader, 2000, 291-316. Retrieved January 29, 2018.

Jung, C. The Archetypes and the Collective Unconscious (2nd ed.) (R. Hull, Trans.). Princeton, NJ:

Princeton University Press, 1990.

Jung, C. G., and Robert Alan. Segal. On Mythology. London: Routledge, 1998.

Jung, C. G., Von Franz, M. L., Henderson, J. L., Jacobi, J., \& Jaffe, A. Man and his Symbols. New York, NY: Ferguson Publishing, 1964.

Walker-Jones, A. "Eden for Cyborgs: Ecocriticism and Genesis 2-3.” Biblical Interpretation, 16(3), 2008, 263-293. 